Original article

\title{
EFFECTS OF DIAZINON ON SOME INNATE RESISTANCE PARAMETERS IN THE CASPIAN POND TURTLE (MAUREMYS CASPICA CASPICA)
}

\author{
S. SOLTANIAN ${ }^{1}$, R. FALLAHI ${ }^{2} \&$ M. S. FEREIDOUNI ${ }^{1}$ \\ ${ }^{1}$ Aquatic Animal Health and Diseases Department, School of Veterinary Medicine, \\ Shiraz University, Shiraz, Iran; ${ }^{2}$ Razi Vaccine and Serum Research Institute, Agri- \\ cultural Research Education and Extension Organization (AREEO), Karaj, Iran
}

\section{Summary}

Soltanian, S., R. Fallahi \& M. S. Fereidouni, 2018. Effects of diazinon on some innate resistance parameters in the Caspian pond turtle (Mauremys caspica caspica). Bulg. J. Vet. Med., 21, No 2, 212-223.

\begin{abstract}
Several experimental studies have been conducted to determine whether environmental stressors, including chemical pollutants, may have immunosuppressive effects and therefore, trigger disease emergence in exposed organisms. The present study aimed to evaluate the effect of diazinon (DZN), a worldwide used organophosphate pesticide, on some immune parameters of Caspian pond turtle (Mauremys caspica caspica). Twenty-four turtles (with a mean body weight of $182.6 \pm 10.8 \mathrm{~g}$ and mean age of 2 years) were randomly distributed in four groups. Three groups were intraperitoneally injected once with three different doses of DZN $(1,10$, or $100 \mathrm{ng} / \mathrm{g}$ body mass), while one was maintained as control ( $1 \mathrm{~mL}$ olive oil injected). Blood samples were taken 1 and 2 weeks post-treatment. A positive correlation was found between diazinon (high dose) concentration and immunosuppressive effects at the $2^{\text {nd }}$ week post exposure as evidenced by lowered serum complement maximum haemolysis ( $\mathrm{MH} \%$ ) (from $57.0 \%$ to $31.5 \%$ ), diminished lysozyme activities (from $6.6 \mathrm{mg} / \mathrm{L}$ to $4.8 \mathrm{mg} / \mathrm{L}$ ), increased heterophil/lymphocyte ratio (from 1.62 to 2.97 ), reduced leukcocyte counts (from $4.46 \times 10^{9} / \mathrm{L}$ to $2.85 \times 10^{9} / \mathrm{L}$ ) as well as phagocytic activity (from $28.16 \%$ to $19.0 \%$ ). The data demonstrated that turtles with high-dose diazinon exposure exhibited immunomodulation.
\end{abstract}

Key words: Caspian pond turtle, complement, diazinon, immunotoxicity, leukocytes

\section{INTRODUCTION}

The organophosphorous pesticides (OPs) were introduced to replace the organochlorine pesticides after the tendency of DDT and its metabolites to bioaccumulate in ecosystems and to cause adverse health effects, particularly in top predators leading to the legal ban or restriction of their use in the 1970s (Galloway \& Handy, 2003).

Diazinon (DZN) (O, O-diethyl-O-[2isopropyl-6-methyl-4-pyrimidinyl] phosphorothioate) is a broad range organo- 
phosphate insecticide, widely used throughout the world in agriculture and horticulture (Garfitt et al., 2002). It is the most commonly used organophosphate insecticide in the world after malathion (Ghafour-Rashidi et al., 2007). In addition to acetylcholinesterase inhibition, DZN can induce oxidative stress, which is important in its toxicity (Amirkabirian et al., 2007; Shadnia et al., 2007). Diazinon is a moderately persistent toxic substance in the environment (Larkin et al., 2000; Bazrafshan et al., 2007), and has been detected in significant amount in many coastal, deltaic and surface waters as well as in municipal wastewater treatment plants around the world, including Iran (Shayeghi et al., 2001; U.S.EPA, 2005). DZN enters into aquatic ecosystems in large amounts and affects non-target organisms (Burkepile, 2000; Maxwell \& Dutta, 2005).

Wildlife immunotoxicology is quite new, and studies examining reptiles have started only in the last decade (Keller et al., 2006). Recent studies have shown that some pesticides are immunotoxic, triggering disease emergence in exposed organisms (Gray et al., 2009; Kerby \& Storfer, 2009; Kreutz et al., 2010; Chen et al., 2011; Polakiewicz \& Goodman, 2013; Carter \& Goodman, 2015).

Considering the acute toxicity of OPs on non-target wildlife species including birds, fish, terrestrial and aquatic vertebrates, relatively little attention has been paid to their immunotoxicity in species other than higher vertebrates (Galloway \& Handy, 2003). Not only are studies limited to species for which adequate immunological testing methods are available, but large differences in species sensitivity to the toxic effects of OPs must be taken into account (Galloway \& Handy, 2002).
Various reports have been published with respect to DZN and its effects on biochemical and haematological parameters of fish (Khoshbavar-Rostami et al., 2006; Koprücü et al., 2006; Alhammaly, 2013). Furthermore, diazinon has also been implicated in immunosuppression in fish and animal models e.g., laboratory rodents (Galloway \& Handy, 2003; GirónPérez et al., 2006; 2007; 2008; 2009; Alhammaly, 2013; Díaz-Resendiz et al., 2015). However, no data were found in literature regarding immunotoxic effects of DZN in turtle species. This is surprising given that turtles have a widespread distribution and are highly aquatic, nonmigratory animals, use habitats near agricultural areas, are carnivores or scavengers, and with long life expectancy (Hopkins, 2000; Moll \& Moll, 2004; Sparling et al., 2010).

Thus, the purpose of the current study was to investigate the effects of DZN on the immune system of Caspian turtles ( $M$. caspica caspica). This species is living in the eastern Mediterranean region from northwestern Saudi Arabia, Iraq, Bahrain, Turkey, Caucasus and Tbilisi to northern, central, and south western part of Iran (Vamberger et al., 2013). It is widely prevalent in different provinces of Iran, e.g., Mazandaran, Golestan, Guilan, Ardabil, Azerbaijan, Kurdistan, Fars, and Khuzestan (Iverson, 1994).

In the current study, it was hypothesised that exposure of $M$. caspica caspica to increasing concentrations of DZN would correlate with a decrease in host immunocompetence, reflected by several non-specific immune responses including heterophil/lymphocyte ratios, peripheral blood leukocyte counts and phagocytic activity, as well as in serum lysozyme and haemolytic complement activities. 
Effects of diazinon on some innate resistance parameters in the Caspian pond turtle ....

\section{MATERIALS AND METHODS}

\section{Experimental design}

The experiment was performed on $M$. caspica caspica with a mean body weight of $192.6 \pm 10.8 \mathrm{~g}$, a mean plastron length of $9.6 \pm 2.4 \mathrm{~cm}$ and a mean age of $2 \pm 1$ years. The age of the animals was calculated by counting the average folds in the shell of the turtles, an accepted method of turtle age calculation (Berry \& Christopher, 2001). The turtles were caught alive from the ponds of the Fars province and were transported to the laboratory of Aquatic Animal Health and Diseases Department, School of Veterinary Medicine, Shiraz University. They were acclimated to laboratory conditions for at least a month.

Turtles were randomly divided into $60 \mathrm{~L}$ tanks (three turtles/tank) held at an average water temperature of $27 \pm 2{ }^{\circ} \mathrm{C}$ with a natural light cycle. Two replicate tanks were used per treatment. Basking platforms were provided in the tanks for the turtles. Water temperature was monitored daily and turtles were fed pelleted rainbow trout feed three times a week. In these experiments, $M$. caspica caspica were allocated randomly into four equal experimental groups $(n=6)$. Three of the groups were treated once with a single intraperitoneal injection of DZN (PESTANAL analytical standard: $\mathrm{C}_{12} \mathrm{H}_{21} \mathrm{~N}_{2} \mathrm{O}_{3} \mathrm{PS}$, purity $99 \%$, Sigma-Aldrich, Laborchemikalien GmbH, Germany). The DZN concentrations employed were: treatment 1 $(\mathrm{DZN100})=100 \mathrm{ng} / \mathrm{g}$ body mass, treatment $2(\mathrm{DZN} 10)=10 \mathrm{ng} / \mathrm{g}$, and treatment $3(\mathrm{DZN} 1)=1 \mathrm{ng} / \mathrm{g}$. As a negative control, the fourth group of turtles injected with vehicle (olive oil) only.

\section{Blood collection}

Blood from all turtles was sampled at the $1^{\text {st }}$ and $2^{\text {nd }}$ weeks post-treatment. Samples were collected from the subcarapacial vein using a $2-\mathrm{mL}$ syringe and a $24-\mathrm{G}$ needle from all six turtles in each sample group. One sample of blood sample was collected into heparinised Eppendorf tubes (10 parts blood: 1 part $1 \mathrm{mg} / \mathrm{mL}$ heparin) while another was collected into a tube without anti-coagulant and allowed to clot for $2 \mathrm{~h}$ at room temperature. The clot was then cut with a glass rod and care taken to avoid haemolysis. The tubes were then placed at $4{ }^{\circ} \mathrm{C}$ overnight, centrifuged at $2500 \times \mathrm{g}$ for $15 \mathrm{~min}$, and the supernatant serum collected. Serum was stored at $-20{ }^{\circ} \mathrm{C}$ until use.

\section{Blood leukocyte counts and ratios}

Blood samples from the heparinised tube were analysed for total leukocyte counts and evaluation of heterophil:lymphocyte ratio (HLR). Total number of leukocytes was counted using a Neubauer chamber. For this, an aliquot of whole blood was diluted $1: 200$ with $0.6 \% \mathrm{NaCl}(\mathrm{w} / \mathrm{v})$ solution (Siroski et al., 2016) that acts as a red cell lysing agent without interfering with leukocyte integrity. For the differential leukocyte counts, two smears on glass slides were prepared from each sample, air-dried, fixed with absolute methanol, and stained with May Grunwald-Giemsa solution. Heterophils and lymphocytes were differentiated out of 300 cells counted at a $1000 \times$ magnification/slide and the their ratio calculated for each turtle.

\section{Phagocytic activity ex vivo}

The ex vivo phagocytic activity of whole blood cells was analysed using commercial baker's yeast, Saccharomyces cerevisiae, as an indicator according to Zhou et al. (2002). Dried live yeasts were incubated in $2 \%$ sucrose solution ( $\mathrm{pH} \mathrm{3-4)}$ for $2 \mathrm{~h}$ at $30{ }^{\circ} \mathrm{C}$ and boiled for $30 \mathrm{~min}$. The yeasts were then centrifuged and the pellet 
washed twice and re-suspended in $0.85 \%$ saline at $2 \times 10^{8}$ cells $/ \mathrm{mL}$. An aliquot of 20 $\mu \mathrm{L}$ of suspension as well as $40 \mu \mathrm{L}$ heparinised whole blood were then added to a $0.1 \mathrm{~mL}$ Eppendorf tube and the mixture incubated at $30{ }^{\circ} \mathrm{C}$ for $30 \mathrm{~min}$ with gentle shaking. After this period, smears were prepared and the air-dried slides then stained with Wright-Giemsa stain. Phagocytic activity (PA) was determined by evaluating 100 phagocytes per slide using a light microscope. A minimum of three slides/turtle was evaluated. The mean PA was calculated as: $100 \% \times$ (number of phagocytic cells with engulfed yeast cells/number of phagocytes counted).

\section{Serum lysozyme activity}

Serum lysozyme activity was determined using the methods described by Jian \& $\mathrm{Wu}$ (2003). In brief, a suspension of an overnight grown Micrococcus lysodeikticus was prepared by dissolving $20 \mathrm{mg} M$. lysodeikticus into $100 \mathrm{~mL}$ of $67 \mathrm{mM}$ sodium phosphate buffer ( $\mathrm{pH}$ 6.4). For the assay, $100 \mu \mathrm{L}$ turtle serum was added to a $3 \mathrm{~mL}$ suspension of $M$. lysodeikticus and the mixture incubated at $25{ }^{\circ} \mathrm{C}$. At reaction time-points of 0.5 and $4.5 \mathrm{~min}$, the absorbance of the sample was measured at $540 \mathrm{~nm}$ in a Biophotometer UV-visible spectrophotometer (Eppendorf, Stevenage, UK). A unit of lysozyme activity was defined as the amount of lysozyme producing a decrease in absorbance of $0.001 / \mathrm{min}$. Lysozyme concentrations were calculated using a standard curve of lysozyme from chicken egg white (Sigma) concentrations.

\section{Serum haemolytic complement assay}

Serum complement activity was determined by the method of sheep red blood cells (SRBC) haemolysis following the protocol of Siroski et al. (2016). In brief,
SRBC were obtained from heparinised whole blood collected from healthy sheep reared at the Veterinary School of Shiraz University. The blood was centrifuged at $3000 \times \mathrm{g}$ and the plasma discarded. The SRBC were re-suspended in phosphatebuffered saline (PBS, pH 7.4) and centrifuged at $3000 \times \mathrm{g}$. The SRBC were then diluted to $2 \%(\mathrm{v} / \mathrm{v})$ in PBS. Turtle serum was then incubated with an equal volume of $2 \% \mathrm{SRBC}(\mathrm{v} / \mathrm{v})$ for $30 \mathrm{~min}$ at $25^{\circ} \mathrm{C}$ for $5 \mathrm{~min}$. Thereafter, the sample was centrifuged at $2500 \times \mathrm{g}$ for $5 \mathrm{~min}$ and then 300 $\mu \mathrm{L}$ of supernatant was recovered to permit measures of optical density in a Power Wave XS2 microplate reader at $540 \mathrm{~nm}$ (BioTek, Winooski, VT). As a positive control, $2 \mu \mathrm{L}$ Triton $\mathrm{X}-100$ was added to $1 \mathrm{~mL}$ of a $1 \%$ SRBC suspension and repeatedly homogenised until complete haemolysis was achieved (maximum haemolysis, MH). The results of SRBC haemolysis in each experiment were divided by the absorbance of the positive control to obtain the maximum percentage of haemolysis $(\% \mathrm{MH})$ and results expressed as mean $\% \mathrm{MH}$.

\section{Statistical analysis}

Data are presented as means \pm SD. Immune parameters were analysed by one-way analysis of variance (ANOVA) and a Tukey's multiple comparison range. All statistical analyses were tested at the 0.05 level of probability using the SPSS 16.0 for Windows software (SPSS, Chicago, IL).

\section{RESULTS}

The total leukocyte analyses showed that control turtles had higher values than those exposed to the pesticide, but these differences were statistically significant only by the $2^{\text {nd }}$ week with the animals from the DZN100 group (Fig. 1). Mean 
Effects of diazinon on some innate resistance parameters in the Caspian pond turtle ....

values for the control turtles were respectively 4.33 and $4.46 \times 10^{9} / \mathrm{L}$ at post treatment weeks 1 and 2. None of the DZN treatments resulted in significantly changed counts one week post-exposure, but the DZN100 regimen induced a significant reduction to $2.85 \times 10^{9} / \mathrm{L}$ by the $2^{\text {nd }}$ week. Overall, there was a dose-dependent trend for the outcomes.

With regard to $\mathrm{H} / \mathrm{L}$ indices, mean values for the control turtles were 1.76 and 1.62 at post exposure weeks 1 and 2 (Fig. 2). The DZN100 regimen induced a sig- nificant increase to 2.44 and 2.97 at post exposure weeks 1 and 2 , respectively. Despite the dose-dependent trend in outcomes, the two other DZN doses had no significant effect on $\mathrm{H} / \mathrm{L}$ ratios at either post-exposure time point.

The percentage of phagocytic activity ex vivo was also affected by treatment of the turtles with the highest used dose of DZN (Fig. 3). Mean values for the control turtles were respectively $27.0 \%$ and $28.16 \%$ at the 1 and 2 week post exposure time points. None of the DZN treatments

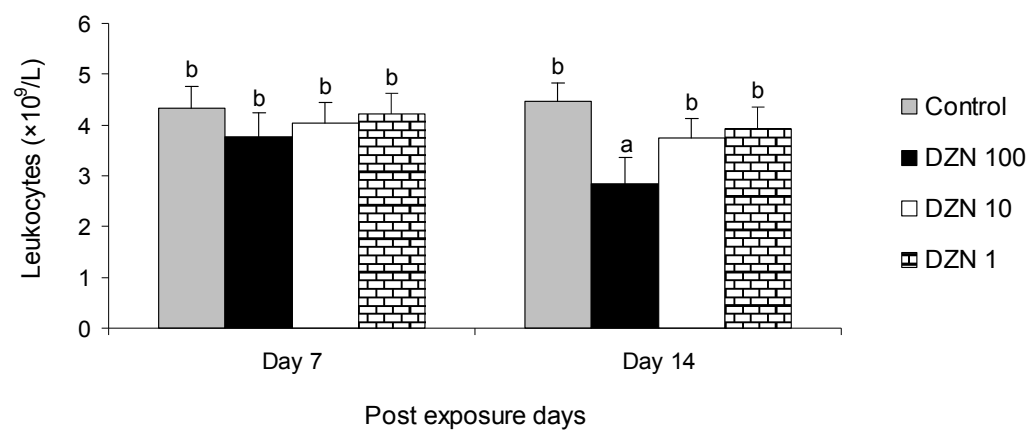

Fig. 1. Total leukocyte counts $\left(\times 10^{9} / \mathrm{L}\right)$ in Caspian pond turtles injected intraperitoneally with different concentrations of diazinon $(1 \mathrm{ng} / \mathrm{g}, 10 \mathrm{ng} / \mathrm{g}$ and $100 \mathrm{ng} / \mathrm{g})$ on post treatment weeks 1 and 2 . Data are presented as mean $\pm \mathrm{SD}(\mathrm{n}=6)$. Means with different letters over the bars are statistically significantly different $(\mathrm{P}<0.05)$.

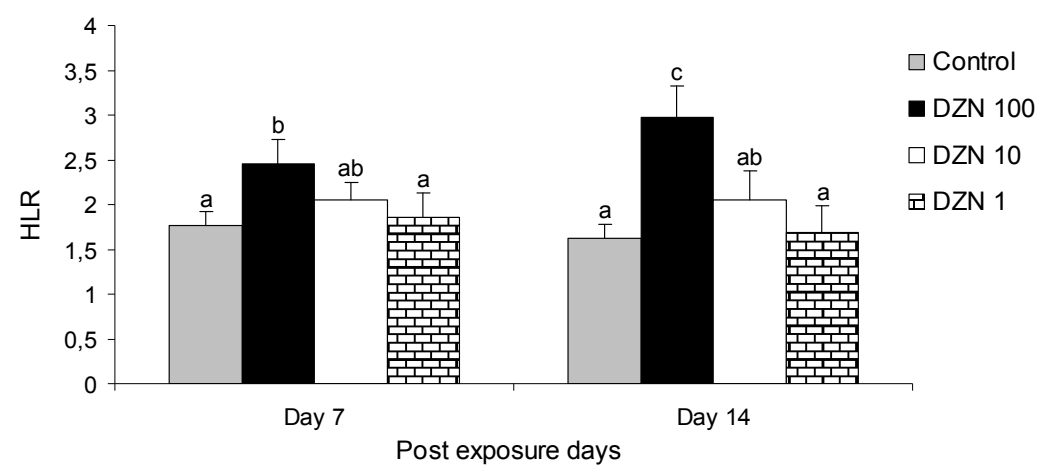

Fig. 2. Heterophil-lymphocyte ratio (HLR) in Caspian pond turtles injected intraperitoneally with different concentrations of diazinon ( $1 \mathrm{ng} / \mathrm{g}, 10 \mathrm{ng} / \mathrm{g}$ and $100 \mathrm{ng} / \mathrm{g})$ on post treatment weeks 1 and 2 . Data are presented as mean $\pm \mathrm{SD}(\mathrm{n}=6)$. Means with different letters over the bars are statistically significantly different $(\mathrm{P}<0.05)$. 


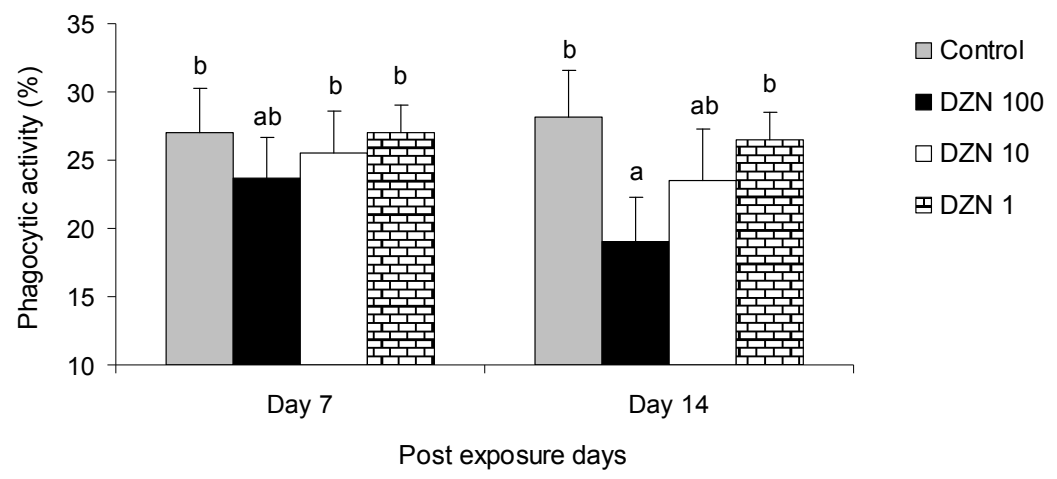

Fig. 3. Phagocytic activity (\%) of the leukocytes of Caspian pond turtles injected intraperitoneally with different concentrations of diazinon $(1 \mathrm{ng} / \mathrm{g}, 10 \mathrm{ng} / \mathrm{g}$ and $100 \mathrm{ng} / \mathrm{g})$ on post treatment weeks 1 and 2. Data are presented as mean $\pm \mathrm{SD}(\mathrm{n}=6)$. Means with different letters over the bars are statistically significantly different $(\mathrm{P}<0.05)$.

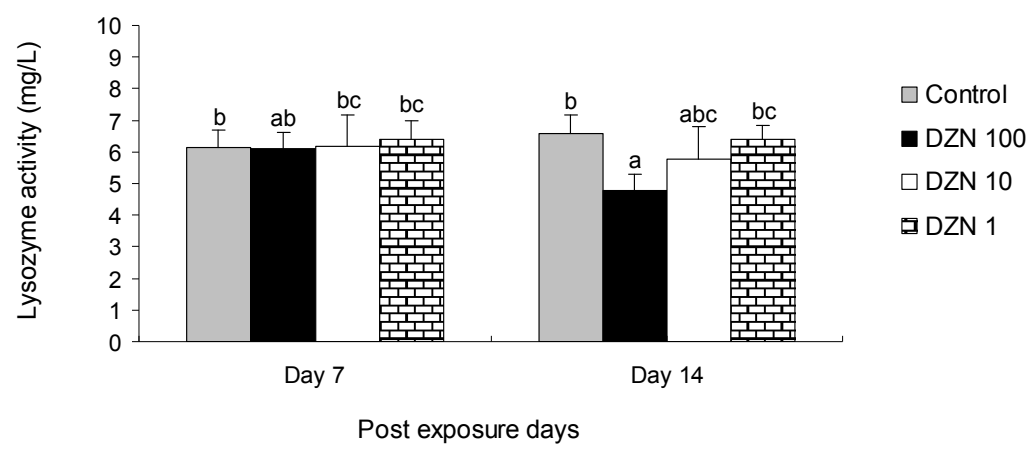

Fig. 4. Serum lysozyme activity $(\mathrm{mg} / \mathrm{L})$ in Caspian pond turtles injected intraperitoneally with different concentrations of diazinon $(1 \mathrm{ng} / \mathrm{g}, 10 \mathrm{ng} / \mathrm{g}$ and $100 \mathrm{ng} / \mathrm{g})$ on post treatment weeks 1 and 2 . Data are presented as mean $\pm \mathrm{SD}(\mathrm{n}=6)$. Means with different letters over the bars are statistically significantly different $(\mathrm{P}<0.05)$.

led to significant changes from these values by the first week.

A similar pattern of effects was also noted with regard to lysozyme activity (Fig. 4) - a significant reduction to 4.8 $\mathrm{mg} / \mathrm{L}$ by the end of the second week after the treatment.

Unsensitised SRBC assay conducted to characterise the complement activity in M. caspica caspica exposed to different DZN concentrations showed mean values in control turtles of respectively 64.3 and
57.0 at both time points (Fig. 5), along with a significant reduction to 31.5 after 2 weeks in the group receiving the highest tested DZN dose.

\section{DISCUSSION}

Haematological investigations are important to wildlife as they can exhibit the health condition of the populations (Gilbertson et al., 2003). In the current study, exposure to DZN induced a de- 


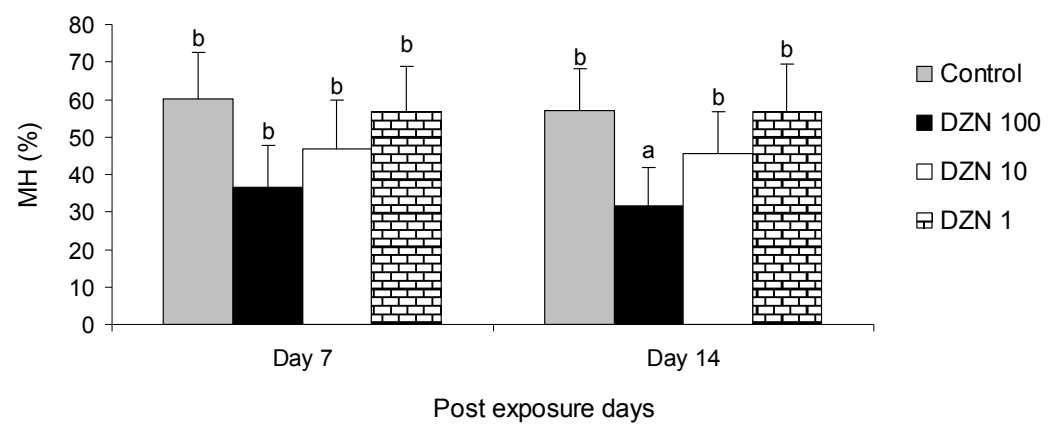

Fig. 5. Serum complement activity expressed as percentage of maximal sheep red blood cells haemolysis $(\% \mathrm{MH})$ of Caspian pond turtles injected intraperitoneally with different concentrations of diazinon $(1 \mathrm{ng} / \mathrm{g}, 10 \mathrm{ng} / \mathrm{g}$ and $100 \mathrm{ng} / \mathrm{g})$ on post treatment weeks 1 and 2. Data are presented as mean $\pm \mathrm{SD}(\mathrm{n}=6)$. Means with different letters over the bars are statistically significantly different $(\mathrm{P}<0.05)$.

crease in the total leukocytes in turtles, with the lowest count observed after exposure to the highest DZN concentration (DZN100 treatment).

A similar decrease in leukocyte counts was observed in rodents intoxicated with other organophosphates, such as chlorpyrifos and monocrotophos (Janardhan \& Sisodia, 1990; Elelaimy et al., 2012). Also, exposure to glyphosate (Roundup ${ }^{\mathbb{R}}$ ) - an OP herbicide, induced a decrease in total leukocyte counts in newborn broad snouted caiman (Caiman latirostris) (Siroski et al., 2016). In a similar study in red eared slider turtles, total white blood cell (WBC) counts were negatively correlated with concentrations of total polychlorinated biphenyls (PCBs) and Arochlor 1260 (Yu et al., 2012). Conversely, a study on loggerhead sea turtles reported that estimated WBC correlated positively with levels of total PCBs and total TCDDlike PCBs (2, 3, 7, 8-tetrachlorodibenzop-dioxin), respectively (Keller et al., 2004).

An increase in the heterophil/lymphocyte $(\mathrm{H} / \mathrm{L})$ index is a common response to stress caused by different factors, espe- cially in birds and reptiles (Latorre et al., 2013). In the present study, the $\mathrm{H} / \mathrm{L}$ index was significantly higher in the animals from the group exposed to highest concentration of diazinon (DZN100 treatment) compared to controls, suggesting that pesticide exposure induced a state of stress. Similar results were reported in newborn broad snouted caiman exposed to glyphosate (Latorre et al., 2013). Likewise, a positive correlation was found between $\mathrm{H} / \mathrm{L}$ ratio and the concentration of total PCBs and total TCDD-like PCBs in loggerhead sea turtles (Keller et al., 2004). Furthermore, green turtles (Chelonia mydas) with fibro-papillomas showed a significant increase in $\mathrm{H} / \mathrm{L}$ ratios that positively correlated with increases in their blood corticosterone levels (Aguirre et al., 1995), providing further evidence of the impact of chronic stress on reptilian immune parameters (Aguirre et al., 1995). Merchant et al. (2006) reported that the American alligator (Alligator mississippiensis) injected with bacterial lipopolysaccharides had increased H/L index values. 
Phagocytosis and killing activity by macrophages is an important defense mechanism against pathogenic bacteria (Rao et al., 2006). In the present study, high-dose treatment with DZN significantly impaired phagocytic activity. Likewise, the phagocytic index of mononuclear cells of Nile tilapia (Oreochromis niloticus) decreased after exposure to diazinon and chlorpyrifos (Girón-Pérez et al., 2006; 2009). It was suggested that phagocytic parameters were more sensitive than haematological ones in assessing the toxicity of the insecticides (GironPerez et al., 2006).

Experiments on albino outbred rats showed that chronic poisoning with organophosphorus compounds (Russian $\mathrm{VX}$, and sarin) resulted in reduction of functional activity of monocyte phagocytic system. This was stipulated by the stimulation of $\mathrm{N}$-cholinergic receptors of these cells. These changes were accompanied by a decrease in blood concentration of pro-inflammatory cytokines (TNF- $\alpha$, IL-1 $\beta$, and IL-6) (Zabrodskii et al., 2013).

Various types of lysozyme have been isolated from several reptilian species (Zimmerman et al., 2010). Circulating lysozyme is a marker of pro-inflammatory responses, has antibacterial functions, and is a measure of innate immunity (Weeks et al., 1992; Burton et al., 2002). In the current work, lysozyme activity was affected by diazinon exposure, and was significantly reduced after DZN100 treatment. Although several studies have addressed the negative effects of diazinon on lysozyme activity in fish species (Khoshbavar-Rostami, 2006; Soltani \& Pourgholam, 2007; Girón-Pérez et al., 2009; Ahmadi et al., 2014; Sharifian et al., 2015), similar data, however, are limited in reptiles.
In one study in loggerhead sea turtles (Caretta caretta), serum lysozyme activity was positively correlated with brevetoxin concentrations measured in the blood of rescued turtles that suffered through a red tide toxin exposure (Walsh et al., 2010). Conversely, in the same species, lysozyme activity was significantly but negatively correlated with whole blood concentrations of organochlorine (OC). Although the mechanism of altered lysozyme activity is not understood, the data suggest that heterophil function might be affected in different ways after exposure to contaminants (Yu et al., 2012).

In the present study, a positive correlation was found between DZN concentration and inhibition of the complement activity in Caspian pond turtle. The highest concentration of herbicide (i.e., DZN100 treatment) resulted in the greatest inhibition of SRBC haemolysis. A previous study showed that newborn broad snouted caimans (Caiman latirostris) exposed to glyphosate exhibited a decrease in the responses of their complement system activities (Siroski et al., 2016). Previously, a deregulation at concentration and mRNA expression of $\mathrm{C} 3$ complement molecule has been reported in anterior kidney, spleen, and plasma of common carps (C. carpio) exposed acutely to chlorpyrifos (Li et al., 2013).

In a study, Casale et al. (1989) compared several organophosphate compounds for their ability to inhibit human serum complement-mediated lysis of sheep red blood cells (SRBCs). Therefore, activity of complement system could be used as an indicator of toxicities induced by pesticides and, potentially, by other environmental factors, but clearly a wide range of endpoints would still need to be evaluated to substantiate the characterisation of an agent as immunotoxic. 
Effects of diazinon on some innate resistance parameters in the Caspian pond turtle ....

In conclusion, the fact that diazinon exposure was positively correlated with the extent of immunosuppression induced in Caspian pond turtles provides evidence that turtles with elevated diazinon exposure undergo immunomodulation, and probably become more susceptible to infection and increasing mortality in the wild.

\section{ACKNOWLEDGEMENTS}

This study was supported by the Aquatic Animal Health \& Diseases Department, School of Veterinary Medicine at Shiraz University through a research grant to the first author.

\section{REFERENCES}

Aguirre, A. A., G. H. Balazs, T. R. Spraker \& T. S. Gross, 1995. Adrenal and hematological responses to stress in juvenile green turtles (Chelonia mydas) with and without papillomas. Physiological Zoology, 68, 831-854.

Ahmadi, K., A. R. Mirvaghefei, M. Banaee, \& A. R. Vosoghei, 2014. Effects of longterm Diazinon exposure on some immunological and haematological parameters in rainbow trout Oncorhynchus mykiss (Walbaum, 1792). Toxicology and Environmental Health Sciences, 6, 1-7.

Alhammaly, E. M., 2013. Effects of the insecticide diazinon and its interactions with supplementations of vitamin $\mathrm{C}$ and vitamin $\mathrm{E}$ on some hematological, biochemical and histopathological charcterstics of Clarias gariepinus. Zoology department, Ph.D thesis. Assiut University, Assiut, Egypt, pp. 158.

Amirkabirian, N., F. Teimouri, H. Esmaily, A. Mohammadirad, A. Aliahmadi \& M. Abdollahi, 2007. Protection by pentoxifylline of diazinon-induced toxic stress in rat liver and muscle. Toxicology Mechanisms and Methods, 17, 215-221.
Bazrafshan, E., A. Mahvi, S. Nasseri \& M. Shaieghi. 2007. Performance evaluation of electrocoagulation process for Diazinon removal from aqueous environments by using iron electrodes. Iranian Journal of Environmental Health Science \& Engineering, 4, 127-132.

Berry, K. H., \& M. M. Christopher, 2001. Guidelines for the field evaluation of desert tortoise health and disease. Journal of Wildlife Diseases, 37, 427-450.

Burkepile, D. E., M. T. Moore \& M. M. Holland, 2000. The susceptibility of five nonmarket organisms to aqueous Diazinon exposure. Bulletin of Environmental Contamination Toxicology, 64, 114-121.

Burton, J. E., I. R. Dorociak, T. E. Schwedler \& C. D. Rice, 2002. Circulating lysozyme and hepatic CYP1A activities during chronic dietary exposure to tributyltin (TBT) and 3, 3', 4, 4', 5pentachlorobiphenyl (PCB-126) mixtures in channel catfish Ictalurus punctatus. Journal of Toxicology and Environmental Health, 65, 589-602.

Carter, E. D. \& R. M. Goodman, 2015. Effects of chemical pollutants and an emerging infectious disease on juvenile red-eared slider turtles (Trachemys scripta elegans). The Hampden-Sydney College Journal of the Sciences, vol. IV, http://blogs.hsc.edu/ sciencejournal/files/2015/03/Carter-D.pdf (31 October 2016 date last accessed).

Casale, G. P., S. Bavari \& J. Connolly, 1989. Inhibition of human serum complement activity by diisopropylfluorophosphate and selected anticholinesterase insecticides. Fundamental and Applied Toxicology, 12, 460-468.

Chen, G. \& J. Robert, 2011. Anti-viral immunity in amphibians. Viruses, 3, 2065-2086.

Díaz-Resendiz, K. J. G., G. A. Toledo-Ibarra \& M. I. Girón-Pérez, 2015. Modulation of immune response by organophosphorus pesticides: Fishes as a potential model in immunotoxicology. Journal of Immunology Research, http://dx.doi.org/10.1155/ 2015/213836 
Elelaimy, I. A., H. M. Ibrahim, F. R. Abdel Ghaffar \& Y. S. Alawthan, 2012. Evaluation of sub-chronic Chlorpyrifos poisoning on immunological and biochemical changes in rats and protective effect of eugenol. Journal of Applied Pharmaceutical Science, 2, 51-61.

Galloway, T. \& R. Handy, 2003. Immunotoxicity of organophosphorous pesticides. Ecotoxicology, 12, 345-363.

Garfitt, S. J., K. Jones, H. J. Mason \& J. Cocker, 2002. Exposure to the organophosphate Diazinon: Data from a human volunteer, study with oral and dermal doses. Toxicology Letters, 134, 105-113.

Gilbertson, M. K., G. Haffner, G. D. Drouillard, A. Albert \& B. Dixon, 2003. Immunosuppression in Northern leopard frog (Rana pipiens) induced by pesticide exposure. Environmental Toxicology and Chemistry, 22, 101-110.

Ghafour-Rashidi, Z., E. Dermenaki-Farahani, A. Aliahmadi, H. Esmaily, A. Mohammadirad, S. N. Ostad \& M. Abdollahi, 2007. Protection by cAMP and cGMP phosphodiesterase inhibitors of diazinoninduced hyperglycemia and oxidative/nitrosative stress in rat Langerhans islets cells: Molecular evidence for involvement of noncholinergic mechanisms. Pesticide Biochemistry and Physiology, 87, 261-270.

Girón-Pérez, M. I., R. Barcelós-García, Z. G. Vidal-Chavez, C. A. Romero-Bañuelos \& M. L. Robledo-Marenco, 2006. Effect of chlorpyrifos on the hematology and phagocytic activity of Nile Tilapia cells (Oreochromis niloticus). Toxicology Mechanisms and Methods, 16, 495-499.

Girón-Pérez, M. I., G. Zaitseva, J. Casas-Solis \& A. Santerre, 2008. Effects of diazinon and diazoxon on the lymphoproliferation rate of splenocytes from Nile tilapia (Oreochromis niloticus): The immunosuppresive effect could involve an increase in acetylcholine levels. Fish \& Shellfish Immunology, 25, 517-521.

Girón-Pérez, M. I., J. Velázquez-Fernández, K. Díaz-Resendiz, F. Díaz-Salas, C. Can-
toMontero, I. Medina-Díaz, M. RobledoMarenco, A. Rojas-García \& G. Zaitseva, 2009. Immunologic parameters evaluations in Nile tilapia (Oreochromis niloticus) exposed to sub-lethal concentrations of Diazinon. Fish \& Shellfish Immunology, 27, 383-385.

Gray, M. J., D. L. Miller \& J. T. Hoverman, 2009. Ecology and pathology of amphibian ranaviruses. Dieases of Aquatic Organisms, 87, 243-266.

Hopkins, W. A., 2000. Reptile toxicology: Challenges and opportunities on the last frontier in vertebrate ecotoxicology. Environmental Toxicology and Chemistry, 19, 2391-2393.

Iverson, J. B., 1994. Variation in East-Asian turtles of the genus Mauremys. Journal of Herpetology, 28, 178-187.

Janardhan, A. \& P. Sisodia, 1990. Monocrotophos: Short-term toxicity in rats. Bulletin of Environmental Contamination and Toxicology, 44, 230-239.

Jian, J., \& Z. Wu, 2004. Influence of traditional Chinese medicine on non-specific immunity of giant carp (Cyprinus carpio var. giant). Fish \& Shellfish Immunology, 16, 185-191.

Keller, J. M., J. R. Kucklick \& P. D. McClellan-Green, 2004. Organochlorine contaminants in logger-head sea turtle blood: Extraction techniques and distribution among plasma and red blood cells. Archives of Environmental Contamination and Toxicology, 46, 254-264.

Keller, J. M., P. D. McClellan-Green, J. R. Kucklick, D. E. Keil \& M. M. PedenAdams, 2006. Effects of organochlorine contaminants on loggerhead sea turtle immunity: Comparison of correlative field study and in vitro exposure experiments. Environmental Health Perspectives, 114, 70-76.

Kerby, J. L., \& A. Storfer, 2009. Combined effects of atrazine and chlorpyrifos on susceptibility of the tiger salamander to $\mathrm{Am}$ bystoma tigrinum virus. EcoHealth, 6, 9198 . 
Effects of diazinon on some innate resistance parameters in the Caspian pond turtle ....

Khoshbavar-Rostami, H. A., M. Soltani \& H. M. D. Hassan, 2006. Immune response of great sturgeon (Huso huso) subjected to long-term exposure to sub-lethal concentration of the organophosphate, diazinon. Aquaculture, 256, 88-94.

Koprücü, S. O., K. Koprücü, M. S. Ural, E. Ispir \& M. Pala, 2006. Acute toxicity of organophosphorous pesticide diazinon and its effects on behavior and some hematological parameters of fingerling European catfish (Silurus glanis). Pesticide Biochemistry and Physiology, 86, 99-105.

Kreutz, L. C., L. J. Barcellos, A. Marteninghe, E. D. Dos Santos \& R. Zanatta, 2010. Exposure to sub-lethal concentration of glyphosate or atrazine-based herbicides alters the phagocytic function and increases the susceptibility of silver catfish fingerlings (Rhamdia quelen) to Aeromonas hydrophila challenge. Fish \& Shellfish Immunology, 29, 694-697.

Larkin, D. J. \& R. S. Tjeerdema, 2000. Fate and effects of diazinon. Reviews of Environmental Contamination and Toxicology, 166, 49-82.

Latorre, M. A., E. C. Gonzalez, A. Larriera, G. L. Poletta \& P. A. Siroski, 2013. Effects of in vivo exposure to Roundup on immune system of Caiman latirostris. Journal of Immunotoxicology, 10, 349-354.

Li, X., L. Liu, Y. Zhang, Q. Fang \& Y. Li, 2013. Toxic effects of chlorpyrifos on lysozyme activities, the contents of complement $\mathrm{C} 3$ and $\mathrm{IgM}$, and $\mathrm{IgM}$ and complement $\mathrm{C} 3$ expressions in common carp $(\mathrm{Cy}$ prinus carpio L.). Chemosphere, 93, 428433.

Maxwell, B. L., \& H. M. Dutta, 2005. Diazinon-induced endocrine disruption in bluegill sunfish, Lepomis macro Chris. Ecotoxicology and Environmental Safety, 60, 21-27.

Merchant, M. E., K. Mills, S. Williams, F. Kleckley, A. Sims, R. M. Elsey \& J. Bushnell, 2006. Effects of bacterial lipopolysaccharide on peripheral leukocytes in the American alligator (Alligator mississip- piensis). Veterinary Immunology and Immunopathology, 111, 315-320.

Moll, D. \& E. Moll, 2004. The ecology, exploitation, and conservation of river turtles. Oxford University Press, New York.

Polakiewicz, F. J. \& R. M. Goodman, 2013. The effects of environmental stressors and the pathogen Ranavirus on survival and health of juvenile freshwater turtles. The Hampden-Sydney College Journal of the Sciences, 1, 1-6.

Rao, Y., B. Das, P. Jyotyrmayee \& R. Chakrabarti, 2006. Effect of Achyranthes aspera on the immunity and survival of Labeo rohita infected with Aeromonas hydrophila. Fish \& Shellfish Immunology, 20, 263-273.

Shadnia, S., M. Dasgar, S. Taghikhani, A. Mohammadirad, R. Khorasani \& M. Abdollahi, 2007. Protective effects of alphatocopherol and n-acetyl-cysteine on Diazinon-induced oxidative stress and acetylcholinesterase inhibition in rats. Toxicology Mechanisms and Methods, 17, 109115.

Sharifian, I., A. Rastiannasab \& H. Gandomkar, 2015. Effects of diazinon on some immunological components of common carp, Cyprinus carpio juveniles. Comparative Clinical Pathology, 24, 1339-1341.

Shayeghi, M., S. J. Shahtaheri \& M. Selseleh, 2001. Phosphorous insecticides residues in Mazandaran River Waters, Iran. Iranian Journal of Public Health, 30, 115-118.

Siroski, P. A., G. L. Poletta, M. A. Latorre, M. E. Merchant, H. H. Ortega \& M. D. Mudry, 2016. Immunotoxicity of commercial-mixed glyphosate in broad snouted caiman (Caiman latirostris). ChemicoBiological Interactions, 244, 64-70.

Soltani, M., \& R. Pourgholam, 2007. Lysozyme activity of grass carp (Ctenopharingodon idella) following exposure to sublethal concentrations of organophosphate, diazinon. Veterinary Research, 62, 50-52.

Sparling, D. W., G. Linder, C. A. Bishop \& S. K. Krest, 2010. Recent advancements in amphibian and reptile ecotoxicology. In: Ecotoxicology of Amphibians and Rep- 
tiles, $2^{\text {nd }}$ edn, eds D. W. Sparling, G. Linder, C. A. Bishop \& S. K. Krest, SETAC Press, Pensacola, pp. 1-11.

Svoboda, M., V. Luskova, J. Drastichova \& V. Zlabek, 2001. The effect of diazinon on haematological indices of common carp (Cyprinus carpio L.). Acta Veterinaria Brno, 70, 457- 465.

U.S. EPA, 2005. Office of Science and Technology Washington, DC. Aquatic life ambient water quality criteria, Diazinon, Final (CAS Registry Number 333-41-5).

Vamberger, M. H., H. Stuckas, D. Ayaz, E. Gracia, A. A. Aloufi, J. Els, L. F. Mazanaeva, H. G. Kami \& U. Fritz, 2013. Conservation genetics and phylogeography of the poorly known Middle Eastern terrapin Mauremys caspica (Testudines: Geoemydidae). Organisms Diversity \& Evolution, 13, 77-85.

Walsh, C. J., S. R. Leggett, B. J. Carter \& C. Colle, 2010. Effects of brevetoxin exposure on the immune system of loggerhead sea turtles. Aquatic Toxicology, 97, 293303.

Weeks, B. A., D. P. Anderson, A. P. Du Four, A. Fairbrother, A. J. Goven, G. P. Lahvis \& G. Peters, 1992. Immunological biomarkers to assess environmental stress. In: Biomarkers: Biochemical, Physiological, And Histological Markers of Anthropogenic Stress, eds R. J. Huggett, R. A. Kimerle, P. M. Mehrle \& H. L. Bergman, Lewis Publishers, London, pp. 211-234.

Yu, S., R. S. Halbrook \& D. W. Parling, 2012. Accumulation of polychlorinated biphenyls (PCBs) and evaluation of hematological and immunological effects of PCBs exposure on turtles. Bulletin of Environmental Contamination and Toxicology, $\mathbf{8 8}$, 823-827.
Zabrodskii, P. F., V. A. Grishin \& V. K. Borodavko, 2013. Mechanism of suppression of phagocytic and metabolic activity of neutrophils and production of proinflammatory cytokines during chronic poisoning with organophosphorus compounds. Bulletin of Experimental Biology and Medicine, 155, 464-466.

Zhou, X., C. Niu, R. Sun \& Q. Li, 2002. Effect of vitamin $\mathrm{C}$ on non-specific immune response of juvenile soft-shelled turtle Trionyx sinensis. Comparative Biochemistry and Physiology, 131A, 917-922.

Zimmerman, L. M., L. A. Vogel \& R. M. Bowden, 2010. Commentary understanding the vertebrate immune system: Insights from the reptilian perspective. Journal of Experimental Biology, 213, 661-671.

Paper received 07.05.2016; accepted for publication 30.09.2016

\section{Correspondence:}

Siyavash Soltanian

Aquatic Animal Health \& Diseases Department School of Veterinary Medicine, Shiraz University, 71441-69155 Shiraz, Iran. tel: +98 $7136138906,+989173364632$, fax: +987132286950

e-mail: siyavashsoltanian@yahoo.com 